\title{
WHAT IS A PHILOSOPHICAL QUESTION?
}

\author{
LUCIANO FLORIDI
}

\begin{abstract}
There are many ways of understanding the nature of philosophical questions. One may consider their morphology, semantics, relevance, or scope. This article introduces a different approach, based on the kind of informational resources required to answer them. The result is a definition of philosophical questions as questions whose answers are in principle open to informed, rational, and honest disagreement, ultimate but not absolute, closed under further questioning, possibly constrained by empirical and logico-mathematical resources, but requiring noetic resources to be answered. The article concludes with a discussion of some of the consequences of this definition for a conception of philosophy as the study (or "science") of open questions, which uses conceptual design to analyse and answer them.
\end{abstract}

Keywords: conceptual design, noetic resources, open questions, philosophy of information, Russell, semantic artefacts.

\section{Introduction: Russell's "such ultimate questions"}

In 1912, Russell published The Problems of Philosophy (Russell 1912). A hundred years later, it is still a classic introduction to philosophy, accessible to beginners and insightful for experts. As the reader probably knows, it is a tiny book. In such a short space, Russell explicitly chooses to privilege epistemological problems over metaphysical ones: "In the following pages," he writes in the preface, "I have confined myself in the main to those problems of philosophy in regard to which I thought it possible to say something positive and constructive, since merely negative criticism seemed out of place. For this reason, theory of knowledge occupies a larger space than metaphysics in the present volume, and some topics much discussed by philosophers are treated very briefly, if at all" (Russell 1912, n.p.). Such an epistemological orientation makes the book especially suitable for an informational interpretation, as the analysis of the problem of sense data shows, for example. Yet, in this article, I do not wish to engage with Russell's selection of philosophical questions, with his own formulation of them, or even with the answers he advocates. Instead, I intend to concentrate on only one paragraph. It is the first of the book, and the following pages may be read, in a Whiteheadian sense (Whitehead 1978, 39), as a long footnote to it: 
Is there any knowledge in the world which is so certain that no reasonable man could doubt it? This question, which at first sight might not seem difficult, is really one of the most difficult that can be asked. When we have realized the obstacles in the way of a straightforward and confident answer, we shall be well launched on the study of philosophy-for philosophy is merely the attempt to answer such ultimate questions [my italics], not carelessly and dogmatically, as we do in ordinary life and even in the sciences, but critically, after exploring all that makes such questions puzzling, and after realizing all the vagueness and confusion that underlie our ordinary ideas. (Russell 1912, 1)

What I intend to present is an interpretation of "such," "ultimate," and "questions" and some of its consequences for our conception of philosophy today. Before I do so, let me remove three sources of potential confusion.

First, I shall follow Russell in not distinguishing between philosophical problems, which he mentions in the preface, and philosophical questions, which he mentions in the first paragraph. I shall assume that the latter are mere linguistic expressions of the former, that this holds true also for the distinction between philosophical solutions and philosophical answers, and hence that the two couples of concepts can safely be used interchangeably. This is less trivial than it may seem because there is a significant difference between heuristics, understood as the method of problem solving (Pearl 1984), and erotetics, that is, the logic of questions and answers (Belnap and Steel 1976).

Second, when talking about philosophical questions and answers, I shall not presuppose them to be equivalent to philosophers' questions and answers. I take the latter to be degenerate cases of the former, to borrow a technical term from mathematics (Floridi 2012b). They can be criticised as expressions of mere scholasticism (Dennett 2006, Floridi 2011).

Third, I agree with Russell that the task of philosophy is twofold: the analysis of questions must precede, but then should also be followed by, the synthesis of answers. A philosophy without clear questions is an abortion, but without convincing answers it is fruitless.

\section{The Variety of Questions}

There are many interesting ways of analysing questions. Some of them easily lend themselves to a metaphilosophical application. In particular, one may begin by concentrating on their morphology, and describe philosophical questions as definitional ("wh- ..." kind of questions) or existential (as in "existential quantifier," not as in Sartre). What is truth? What should I do? Why do we behave altruistically? Who am I? Is there a God? Can there be justice? And because of the classic "ti esti . .." format, one may hold that philosophical questions are therefore Socratic questions. Uygur suggests as much: "My main object is to scrutinize the typical structure of a genuine philosophical question without regard to the stage of 
research it might animate. My chief concern is to describe only the salient characteristics of a philosophical question. I see my task in showing what is contained in such a question; I want to throw light on what is asked in it, trying to point out, as correctly as I can, the basic form of a question proper to philosophy" (Uygar 1964, 65). This is a good start, but it does raise a difficulty: the philosophical specificity of Socratic questions soon appears to lie in their topics rather than in their morphology. For one may object that it is because Socratic questions are about truth, duty, altruism, personal identity, God, or justice that they are philosophical. If so, their philosophical specificity would be primarily a matter of reference: their morphology would be a mere means to a more important end, that of unveiling the problematicity of their conceptual targets. I suppose one could imagine a language in which all wh- and existential questions can only be expressed as propositional wants or needs (e.g., "I need to know that $p$ " or "I must know whether $p$ ") and still fully maintain the philosophical nature of such wants and needs. So perhaps this is correct. Maybe there are intrinsically philosophical contents (sense) or topics (reference) from which relevant questions inherit a corresponding philosophical value, like moons illuminated by their suns. But even this cannot be the whole story. There is still at least one important aspect missing. Even with the right morphology and semantic features, Socratic questions may start from, but are not about, this particular empirical truth, or that idiosyncratic act of altruism. Moreover, in philosophy we do not seek to know whether there is a God or there can be justice in the fantasy world of Tolkien's Lord of the Rings. So scope and relevance are also important. For this reason, we also tend to qualify Socratic questions as abstract, universal, sometimes timeless, ${ }^{1}$ and as important for us, our lives, choices, practical and intellectual pursuits, preferences, and moral behaviours. I am not sure this will not do. Russell seems to have thought that it did. As we shall see in section 7, this is why, I take it, he spoke of philosophical questions as "ultimate questions." Indeed, a careful mixture of morphology, semantics, scope, and relevance has served the philosophical profession well for a long time. So, far be it from me to criticise it. What I would like to suggest is that there is another approach, compatible with the Socratic interpretation outlined above, which can help to clarify further what philosophical questions are and cannot be today. The chronological clause is important. Russell could not have been acquainted with the approach that I wish to advocate, because the latter is based on a simple but groundbreaking lesson we have learned from studies in computational complexity since the 1960s: a lesson that had its roots in the work of Alan

${ }^{1}$ Schlick already had some very convincing arguments against interpreting philosophy as the science of the general or a super-science (Schlick 1932). Yet his arguments seem to have gone unheard: see, for example, Dewey 1956 or Schlette 1968, two cases in which such an interpretation is still quite popular (it is also discussed in Glaeser 1969, rather approvingly), and what Dummett 2010 suggests about Quine and the naturalisation project. 
Turing (Fortnow and Homer 2003), who was born the same year Russell published his book. It seems that 1912 was some kind of accidental threshold.

\section{A Resource-Oriented Approach}

Turing gave us a clear analysis of what an algorithm is. This is crucial in order to shift our perspective on the nature of computational problems, because having a standard way of formulating algorithms means having a universal parameter to calculate the complexity of the problems that such algorithms are supposed to solve. So a Turing machine works a bit like the metre in Paris. The result, a few decades after Turing's groundbreaking research, is that, in computational theory, one investigates the nature of problems by looking at their complexity, understood as the degree of difficulty of solving them, by studying the resources required to solve them. ${ }^{2}$ This means that one does not focus on the specific morphology of the problems - because this is where having a universal model, such as a Turing machine, helps us not to be side-tracked - on their semantic features - because we are interested in whole classes of problems independently of their specific content and topic - or on their scope and relevance - because we are interested in their complexity independently of their timeless applicability. Rather, we investigate the complexity of computational problems by studying the quantity and quality of resources it would take to solve them. This usually means considering the amount of time (number of steps) or space (quantity of memory) required. In this way, it becomes possible to study classes of problems that share the same degree of complexity, and to structure such classes in hierarchies of different degrees of complexity.

The importance of such a shift in perspective may be easily conveyed by means of a simple analogy. When studying animals, one may concentrate on their morphology (e.g., quadruped), or reproductive method (e.g., oviparous), or indeed many other features, such as their habitat (e.g., palustre, or swamp animal). Or one may consider what it takes to keep an animal alive. According to this diet-oriented approach, a class of animals could be catalogued as frugivore, or fruit eater, for example. This is more or less what happens in computational theory: classes of computational problems are organised in terms of their complexity understood as the kind of resources they (would) consume in order to be solved.

The previous analogy should help to clarify the resource-oriented approach adopted below: we can study questions by considering the resources required by their answers. It should also dispel any concern about the strategy I shall follow. It is not my intention to try the

${ }^{2}$ An excellent introduction is provided by Sipser 2012. I have provided a simple and philosophically oriented outline of computational complexity in Floridi 1999. 
impossible, that is, to classify and study philosophical problems on the basis of their computational complexity. On the contrary, later in the article it will become obvious that this should be considered an outdated, Leibnizian dream. In philosophy, there are no experiments and no calculations, for reasons that will soon be obvious. What I wish to borrow, from computational complexity theory, is only the simple yet very powerful insight that the nature of problems may be fruitfully studied by focusing on the kind of resources required in principle to solve them, rather than on their form, meaning, reference, scope, and relevance.

Equipped with this new conceptual tool and a different approach, let us now return to our initial attempt to clarify what a philosophical question is.

\section{Three Kinds of Question}

Although questions may be of many kinds ${ }^{3}$ - think of Socrates's rhetorical questions, for example, or his testing questions - and hence serve a variety of purposes - for example, implicitly asserting that $p$, or explicitly checking whether Alice knows that $p$-it seems clear that, in this context (recall Russell's book), we are discussing questions as genuine requests for information $^{4}$ or queries: we are looking for an answer we do not have but would like to obtain. ${ }^{5}$ It follows that, from a resource-oriented approach, and simplifying a bit, ${ }^{6}$ we may distinguish between different kinds of questions as queries (henceforth I shall drop this qualification), depending on what kind of information it would take it to answer them.

Obviously, some questions require empirical information to be answered, as when Alice asks Bob who is coming to their party on Saturday and whether any guest is vegetarian. Equally obviously, some other questions require logico-mathematical information to be answered, ${ }^{7}$ as

3 Analyses abound. In connection with the nature of philosophical questions, Cohen 1929 already provided a clear analysis of the other senses that I disregard in this article, and further bibliographical references.

4 "The question has usually been described as a request for information" (Cohen 1929, 351); see also Llewelyn 1964 for an analysis of questions as ways to elicit information, what I have called queries.

${ }_{5}^{5}$ The proposal in Cohen 1929 (critically discussed by Llewelyn [1964], but see also Carnap, C. I. Lewis, Reichenbach, Ryle, Hamblin, and Presley) to construe questions as propositional functions is perfectly compatible with the theses defended in this article, but its adoption would merely burden the text with an unnecessary complication.

${ }^{6}$ I am simplifying here because of course hybrid cases are very common, combining features of more than one class (hence my use of the inclusive "or" in the text), but this refinement only makes things more obscure without helping to make the point any more convincing, so I shall rely on the reader's intelligence.

${ }^{7}$ Whether logico-mathematical resources may be defined as logico-mathematical information is a difficult issue because the informational nature of logic and hence mathematics is problematic, see Hintikka's "scandal of deduction" (Hintikka 1973). I shall not discuss this issue here. For a full discussion and a constructive proposal see D'Agostino and Floridi 2009. 
when Alice asks Bob how many people might be coming if the guests' spouses are added, and whether there are enough chairs to seat everybody. However, still other questions may be answered by neither empirical nor logico-mathematical information (or a combination of the two), as when Alice asks Bob whether they should have a party on Saturday at all, or why it may be preferable to organise it on Friday. In this case, no matter how much empirical and logico-mathematical information Bob may use to formulate his answer, he may still fail to address Alice's question. This is repeatedly stressed in many contexts by philosophers of almost any school. To quote Uygur again, "the question 'Is consciousness a mechanism or organism?' requires primarily a thorough investigation of the respective concepts 'mechanism' and 'organism.' The ground for treating philosophical questions is thus not various world-facts - e.g. machines or living beings - but different discourses embodying these concepts" (1964, 67). It gets worse. For Alice might marshal an equal amount of empirical or (inclusive or, I shall not repeat this clarification unless it is necessary) logico-mathematical information to formulate a different answer, and yet she and Bob could still be well informed, reasonable, sensible to each other's perspectives, and honestly willing to compromise. For this reason, I shall call this third kind of questions open. The reader will have guessed that philosophical questions are open questions, in the following sense.

\section{Philosophical Questions as Open Questions}

Empirical and logico-mathematical questions are in principle closed, whereas philosophical questions are in principle open. By this I do not mean to suggest that people necessarily agree on how to answer empirical and logico-mathematical questions (I wish), nor am I suggesting that the relevant empirical or logico-mathematical information is always available as a resource to formulate a correct answer to any empirical and logicomathematical questions (more wishful thinking). What I am suggesting is that empirical and logico-mathematical questions are such that once we have the necessary and sufficient resources to formulate a correct answer, any further disagreement on that formulated answer may speak volumes about the parties involved but says nothing about the answer itself. If Alice and Bob disagree on who or how many people did come to their party, one of them is un- or misinformed, or irrational, or confused, or perhaps just stubborn, or a bit of all. But if they disagree on whether the party should take (or should have taken) place on Friday rather than on Saturday, they may both be perfectly informed, rational, and openminded. Philosophical questions are questions not answerable empirically or mathematically, with observations or calculations. They are open questions, that is, questions that remain in principle open to informed, rational, and honest disagreement, even after all the relevant observations 
and calculations have become available and the answers have been formulated.

Let us suppose for the moment that such definition is entirely correct (it is not, and it will need to be refined). Assuming that some questions are indeed open, how can we recognise them? A good test for the genuinely open nature of a question may look like the following.

Recall that questions are here understood as genuine requests for information. In ordinary circumstances - for example, barring circumstances in which one may wish to double-check whether one has received the correct piece of information, and so on - if the communication goes well and one receives the requested information, it would be unreasonable to reiterate the question. If Alice asks Bob: "How many people are coming to the party?" and Bob answers, "Eight," then, in ordinary circumstances, assuming that Alice has fully and clearly understood Bob's answer, it would be unreasonable of Alice to reiterate the question, because she could not hope to be better informed by doing so. To use Wittgenstein's analogy, she would be buying another issue of the same newspaper to double-check the news. Not a smart move. However, if it is reasonable to reiterate the question, as a request for further information, after having received any amount of relevant empirical or logico-mathematical information, then clearly one is asking a question that cannot be satisfied by the answer just received. Now this is what happens with open questions. Bob may ask to Alice why they are organising a party on Saturday, and all the empirical facts or observations and logico-mathematical proofs or calculations available will not make it unreasonable to keep asking the typical "yes, but ..." question: "Yes, I understand, but why are we organising a party on Saturday?" The careful reader will recognise in this test of "reasonably reiterable query" a family resemblance with the open question argument developed by E. G. Moore in his Principia Ethica to deal with the naturalistic fallacy. ${ }^{8}$ The affinity is strong, and not accidental, since in both cases it is a form of antinaturalism that is driving the reasoning. I shall return to it in section 7, when discussing the nature of philosophical questions as ultimate open questions, closed under questioning.

The definition of philosophical questions as open questions is a first approximation that needs to be refined, since it needs to be defended against four main objections. This will be the task of sections $6,7,8$, and 9 , respectively. At the end of such a defence, the definition will be more precise and cogent. But it will still need to be unpacked in order to see its implications. This task is left to section 10, which concludes the article. Before we look at the objections and replies, the definition can already be used to stop some vandalism: Hume's.

The reader will recall the following, famous quotation from Hume: "When we run over libraries, persuaded of these principles, what havoc

${ }^{8}$ For a recent presentation see Strandberg 2004. 
must we make? If we take in our hand any volume; of divinity or school metaphysics, for instance; let us ask, does it contain any abstract reasoning concerning quantity or number? Does it contain any experimental reasoning concerning matter of fact and existence?" (my italics; Hume 2000, sec. XII, part III, 165). Hume's "experimental reasoning concerning matter of fact and existence" and his "abstract reasoning concerning quantity or number" are just the empirical and logico-mathematical information mentioned above. As a consequence, if the answers to Hume's two questions (both empirical, by the way) are affirmative, then what I am suggesting is that we should search elsewhere, because that is science, not yet philosophy. But if the answers are negative, then it would be foolish to follow Hume's pyromaniac advice: "Commit it then to the flames: for it can contain nothing but sophistry and illusion," for we would be throwing into the flames both the baby and the bath water, if only the idiom allowed one to say so. Many questions that are not answerable by means of empirical or logico-mathematical information are also not a matter of "sophistry and illusion." There is much space in between, represented by open (philosophical) questions of the highest importance. Part of the careful task of a philosopher is to disentangle the latter from the former, rather than throwing the whole lot into the fire. Unfortunately, some people disagree and prefer Hume's vandalism. This is the first objection.

\section{First Objection: There Are No Open Questions}

If philosophical questions are open questions, in principle unanswerable empirically or logico-mathematically, one may argue that such a definition is correct but includes too little, indeed nothing at all, and ends up being self-defeating. For one may accept that questions are in principle answerable only by resort to empirical or logico-mathematical information, so that anything else is just reducible confusion (open questions are actually closed) or eliminable nonsense (open questions are actually meaningless). Ultimately, the objection continues, there is no space between questions answerable by facts or observations and questions answerable by proofs or calculations, apart from a combination of the two kinds of resources. If the definition is correct, it makes the set of philosophical questions empty, either because they are reducible to empirical or logico-mathematical questions or because they can be fully eliminated, once they are shown to be meaningless questions: "Thus the fate of all 'philosophical problems' is this: some of them will disappear by being shown to be mistakes and misunderstandings of our language and the others will be found to be ordinary scientific questions in disguise. These remarks, I think, determine the whole future of philosophy" (Schlick 1932, 19). Philosophers have often been the source of such Humean friendly fire. There is a simplistic way of reading the Vienna Circle as supporting a similar kind of intolerant vandalism. I write "simplistic" because philosophers like Schlick were 
much more refined and interpreted philosophy as a necessary semantic activity rather than a science, following Wittgenstein (the ensuing quotation, provided by Schlick, is from the Tractatus, 4.112): "The view which I am advocating has at the present time been most clearly expressed by Ludwig Wittgenstein; he states his point in these sentences: 'The objection of philosophy is the logical clarification of thoughts. Philosophy is not a theory but an activity. The result of philosophy is not a number of "philosophical propositions", but to make propositions clear'. This is exactly the view which I have been trying to explain here" (Schlick 1932, 2:221). The very idea of philosophy as a dissolution of its own problems as pseudoproblems (Sorensen 1993) is sympathetic to this first objection. It is a recurring temptation for impatient people. Recently, one of the most radical and vociferous advocates of such an anti-philosophical position has been Stephen Hawking. In The Grand Design-New Answers to the Ultimate Questions of Life, we read:

We each exist for but a short time, and in that time explore but a small part of the whole universe. But humans are a curious species. We wonder, we seek answers. Living in this vast world that is by turns kind and cruel, and gazing at the immense heavens above, people have always asked a multitude of questions: How can we understand the world in which we find ourselves? How does the universe behave? What is the nature of reality? Where did all this come from? Did the universe need a creator? Most of us do not spend most of our time worrying about these questions, but almost all of us worry about them some of the time. Traditionally these are questions for philosophy, but philosophy is dead. Philosophy has not kept up with modern developments in science, particularly physics. Scientists have become the bearers of the torch of discovery in our quest for knowledge. (Hawking and Mlodinow 2010, 15)

Although this is not the place in which to discuss such a boutade-the reader interested in following the debate about it may find Norris 2011 enlightening - it is worth considering Hawking's position in so far as it helps to clarify the self-reflective nature of philosophical questions and hence answer the first objection.

Hume and Hawking are right in holding that, if one assumes that philosophical questions are closed questions - if philosophy is in the business of dealing with "experimental reasoning concerning matter of fact and existence," "abstract reasoning concerning quantity or number," and "discovery in our quest for knowledge" - then philosophy is dead, because it has (or at least it should have) outsourced the task of answering such questions to investigations that can help themselves to the right empirical or logico-mathematical resources; to science, to put it simply. In light of the previous section, however, it is equally sensible to read the previous inference as a modus tollens: since open questions are not reducible or eliminable, philosophy does not (have to) outsource them, so it is in a 
healthy state and in business. The result is that we are caught in a classic stalemate whereby "one philosopher's modus ponens is another's modus tollens," as the phrase goes. This starts looking like an open question in and of itself, but even if one is still reluctant to step up the metatheoretical level where questions begin to require a different kind of resources to be answerable in principle - impatient arsonists often show such reluctance - it is at least clear that the stalemate can be resolved by agreeing on whether there actually are genuinely open questions. One can use the same appeal to observations and calculations that supporters of the modus tollens advocate, to turn such an argument against them: factually, the burden seems entirely on the shoulders of people like Hawking. For it seems very hard to deny that many, if not most, of the significant and consequential questions we deal with in our life are open. Should Bob propose to Alice? Should they get married? Is it a good idea for them to have children? How can they cope with the loss of their parents? What sense can they make of their life together? Is Alice's career worth Bob's sacrifices? And if Bob later on cheats on Alice, should she forgive him, if he repents? Or should they divorce, even if they have children? Daily, unexciting problems, one may object, that do not deserve to be qualified as philosophical. I disagree, but suppose the objection sticks. There is, of course, a classic move that hinges on the peculiar self-reflective nature of philosophy itself. For, whatever philosophy is, every schoolboy knows that asking this question means philosophising; and every schoolgirl is aware that disagreeing on whether philosophy is dead or alive has the same self-reflective effect of making one do philosophy, therefore providing a practical answer. Likewise, discussing whether there are genuinely open questions is in itself a philosophical question that qualifies as open, thus answering the very question from which it stems. ${ }^{9}$ Questioning is a stepping-up process that sooner or later ends up trespassing on philosophy. A more precise way of understanding this important self-reflective nature of philosophical questions is to realise that philosophical questions are open in terms of disagreement but "closed" under questioning. Let me explain.

Closure is a simple but very powerful concept in mathematics, where we say that a set is closed under an operation if carrying out that operation on members of that set always produces a member of that set. For example, the natural numbers are closed under addition - if you add any natural number you get another natural number - but not under subtraction, and this is why we need the set of negative numbers. Now, the set of philosophical questions is such that if you question such questions, you obtain one more philosophical question. The set of empirical or logicomathematical questions, instead, is not closed but open under questioning:

\footnotetext{
${ }^{9}$ Uygur (1964, 82): “'What is a philosophical question?' is a genuine philosophical question."
} 
carry on the questioning long enough, or by carefully choosing the right questions, and sooner or later you will end up "outside" the set of those questions and inside the set of philosophical ones, which then you can no longer escape by further questioning the questions themselves. Think, for example, of questions about the nature of causality in everyday life and in scientific explanations. The problem with the first objection and with obituary positions $a ̀$ la Hawking is not just that they are merely mistaken but that they are self-contradictory, for bad philosophy is still philosophy.

In light of the first objection, we can refine our definition by saying that philosophical questions are in principle open questions, closed under further questioning. This is better, but unfortunately the new definition still fails to deal with a second difficulty: inflation. If we accept that philosophical questions are open questions, in the disagreement-based sense, and closed questions, in the set-theoretic sense, this may include way too much. We should consider as philosophical questions what to wear when going to Alice and Bob's party, whether one should accept their invitation, whether to bring a bottle of wine or some flowers, or why one was invited even if one is only an acquaintance. The space of philosophical questions would explode, and such an inflation would be evidence that something is wrong with the definition itself. This is the second objection.

\section{Second Objection: There Are Too Many Open Questions}

It may seem that we jumped out of the frying pan into the fire: too many questions now count as philosophical because they are open. A vast variety of mundane uncertainties generate plenty of informed, rational, and honest disagreement. Will there be a financial crisis next year? However one may consider this question, it would be hard to catalogue it as philosophical, and yet it seems open. The concern is sensible, but, in the end, it can be dispelled, for two reasons.

First, uncertainties are not necessarily linked to open questions. Whether there will be a financial crisis next year (or a battle tomorrow, for Aristotle) is a closed question not because we have an answer-we do not by definition, and if we did, we could simply change the example-nor because disagreement, lacking a definite answer, is unreasonable; it is closed because we understand that our lack of a definite answer, and hence our disagreement, is based precisely on insufficient empirical or logicomathematical resources. Had we more empirical or logico-mathematical information, we would have a definite answer, on which it would then be unreasonable to disagree. So much so that by the end of next year (or tomorrow, for Aristotle), we will see that the question was closed. This is why, in section 2, I specified "in principle." Given boundless empirical and logico-mathematical information, in principle Alice and Bob could still 
honestly, informatively, rationally disagree on how they should go (or indeed should have gone) about organising their party, but not about how many people attended it yesterday. The "in principle" clause does an important job.

The second reason concerns the nature or topic of genuinely open questions. Recall that we decided not to pursue such an approach. I have just mentioned the question about the party. It is an open question. Is it also a philosophical one? The answer is yes, but in the same, uninteresting sense in which " $2+2=4$ ?" is a mathematical question. Questions do not have to be highbrow to qualify as philosophical. This is just a cultural prejudice. Philosophical questions, like empirical and logico-mathematical ones, come in a whole variety of degrees of value, importance, relevance, seriousness, difficulty, and so forth. We should approach them without chauvinism. Having said this, it is true that when dealing with philosophical questions we tend to concentrate on more significant and consequential problems than whether we should wear brown or black shoes at the party, no matter how much someone may agonise over this choice. But so do mathematicians and experimental scientists. The conclusion is that, yes, there are plenty of philosophical questions that are rather silly, frivolous, and hence negligible. But sometimes they are the starting point for a full escalation to big philosophical problems. And there are also plenty of empirical or logicomathematical questions that share the same nature. They too, sometimes, lead to huge scientific problems. Why did the apple fall? Why is $1+1=2$ ? It took two Principia to answer such questions. Philosophy tends to deal with the heavy side of the spectrum, but not necessarily, as some ordinary language analysis shows. On the whole, this is why, I take it, Russell added "ultimate" after "such." In order to grasp better the meaning of this qualification, we need to see how questions are connected.

Questions (and their answers) may lead forwards to further questions. For example, "Did you buy six bottles of wine?" may lead to the question "Are you having a party?" which in turn may lead to "Are you celebrating something?" When this happens, one may say that $\mathrm{Q}_{1}$ poses $\mathrm{Q}_{2}$, which poses $\mathrm{Q}_{3}$, and so forth. But questions (and their answers) may also lead backwards, to previous questions: "Did you buy six bottles of wine?" may lead to "Did you buy any wine?" which in turn may lead to "Did you go shopping?" When this happens, one may say that $\mathrm{Q}_{1}$ presupposes $\mathrm{Q}_{-1}$, which presupposes $\mathrm{Q}_{-2}$, and so forth. More formally, erotetic implication - the logical relation interpreting the linguistic relations of "posing" and "presupposing" or of "arising from," in the vocabulary of Wiśniewski (1994) - may be as formally stringent as that of ordinary implication. In the long run, it gives rise to a network, sufficiently loose to admit different topologies but not, for that reason, less robust. So it is a mistake to think that ultimate questions are questions that come first or 
last in time, or at the beginning or the end of a chain of questions. Given the network of questions that mutually pose or presuppose each other, ultimate questions are those questions whose answers are most influential in terms of a cascade of further questions and answers to other related questions within that network. With an analogy, one may say that they are like key pieces in a jigsaw puzzle: once they are placed, it is much easier to locate the other pieces. For example, how one answers the question about the existence of God, or what is a morally good life worth living, has immensely more influence, in terms of how one answers other questions within one's own network, than how one answers the questions about the choice between black or brown shoes, or whether the party should be organized on Friday or on Saturday. Kant spends so much time discussing the question about causality because that is one of the cornerstones of our understanding of the world. Answer that, and a whole wave of consequences follows for other questions. Ultimate questions are therefore attractors, in terms of systems theory: (answers to) less important questions within the system of questions tend to evolve towards (answers to) them over time. In terms of visual metaphors, it is better to imagine philosophical questions at the main nodes of our set of questions, big roundabouts in life's roads.

In light of the second objection, we can further refine our definition by saying that philosophical questions are in principle open, ultimate questions, closed under further questioning. This is even better, but unfortunately the new definition still fails to deal with a third difficulty: scepticism about the available resources. What if philosophical questions, as defined above, cannot be answered because of an inescapable lack of the right kind of information? This is the third objection.

\section{Third Objection: Open Questions Are Unanswerable}

Philosophical questions may be philosophical doubts (see the quotation from Russell in section 1). When they are, they still preserve the features of being open to reasonable disagreement and closed under further doubting. So one can follow Descartes, rely on closure, and deploy doubt to reach certainty about the doubting process itself: radical doubts generate more doubts, but at least this much is certain. The problem, even in a Cartesian-friendly scenario, is not so much that certainty is unreachable in this way but that a purely formal, that is, content-empty, status is all that one can reach safely. The Cogito is like a geometrical point: it has a location in space and time but has no informational extent, that is, it is content-empty (Floridi 1996). If it were not, its informational content could be successfully subject to further doubting, that is, in such a way as to shift further the source of one's own certainty. It is not, and so one can stop there and use it as an Archimedean point, to step back into the content-full, but doubtable, extension of empirical and 
logico-mathematical information. In Descartes, that means adopting the clear and distinct features, shown by the content-empty certainty of the Cogito, as a bridge to re-acquire at least some of the empirical and logicomathematical true contents (information) whose epistemic status was suspended during the doubting process. Philosophers disagree on the soundness of the process (see the so-called Cartesian circle problem) and the reliability of the outcome. The difficulty, in our case, is similar: a sort of stalemate. A sceptic like Sextus Empiricus would not argue against the value of our philosophical questions as defined so far, but he may agree with our definition of philosophical questions exactly in order to object that, given their nature, such open questions remain unanswerable in principle. The only resources we have available are declared by definition insufficient (not unnecessary, more on this presently) to provide an answer. Like Descartes's Cogito - the sceptic may continue-we have reached a safe point of no exit. Thus the fact that this much is granted is not the beginning but the end of the story. So-called ineffabilist interpretations of the Tractatus reach similar conclusions. Or, to use a more Kantian example, we cannot answer questions about the nature of the Ding an sich, because we do not have access to God's information. The conclusion is that philosophical questions remain open not because of the ineliminable possibility of reasonable disagreement in principle, but because there is no way in principle of answering them, and that is because we lack the appropriate informational resources in the first place. The "anything goes" is simply a relativist variant of the same objection: open questions are unanswerable because any answer will do, so no answer really fits. If a lock can be opened by any key, then there is something wrong with the lock.

If you draw the limits of your resources too closely to the questions whose answers need them for the questions to become answerable, you are left only with the questions themselves unanswerable. There are supporters of such a scorched earth objection, but I am not one of them, for a series of concatenated reasons. Before exposing them, let me make one point clear: carefully understood, when this third objection does not reduce to a version of the previous two, in itself it is an objection not against the value of the definition of philosophical questions adopted so far, but rather against the ambitions of a philosophy that seeks to answer them. It needs to be embedded within a reductio in order to work as an objection, somewhat along the following lines: if philosophical questions were so and so, then philosophy would be impossible, but philosophy is possible, so its questions are not so and so. This is usually deployed in order to sever the first half of philosophy's work, the analysis of the questions, from the second half, the synthesis of answers. So the objection as a reductio logically leads to a proposal for a different conception of philosophy, in terms of only the first half, described as conceptual analysis and clarification. As Dummett puts it: 
[In philosophical debates] the matter is not one to be settled by empirical means: scientific theory may bear on it. . . . But science could not resolve the dispute: no observation could establish that one or the other side was right. A philosopher will seek either to show that one of the disputants is right and the other wrong, perhaps after some further clarification of the two views, or else to dissolve the dispute by showing both sides to be victims of some conceptual confusion. Philosophy is indeed concerned with reality, but not to discover new facts about it: it seeks to improve our understanding of what we already know. It does not seek to observe more, but to clarify our vision of what we see. Its aim is, in Wittgenstein's phrase, to help us to see the world aright. (Dummett 2010, 10)

Dummett is right, but note how there is something mysterious in what he suggests: where do the two views come from, if not from philosophy itself? Philosophy so impoverished as to be only analysis without synthesis must implicitly, quietly, silently delegate to others the task of producing the analysanda. It is only a critical and never a constructive enterprise. This seems to be historically incorrect and conceptually disappointing. It is also morally dangerous, as I shall clarify in section 10 . It does remain a viable option, but let me show you why the objection that leads to such a conclusion may be less convincing than it looks, and so why it may be unnecessary to drop the classic conception of philosophy as analysis of questions and synthesis of answers, still endorsed by Russell himself in 1912 (recall: "philosophy is merely the attempt to answer such ultimate questions").

To begin with, the objection is based on a suspicious divide between two alleged sets of open questions: those for which we do have, at least in principle, the required resources to provide an answer, and those for which, allegedly, we do not, even in principle. That the objection presupposes such a divide becomes clear once one realises that, when dealing with the second objection, we acknowledged the fact that there are plenty of simple, ordinary questions that qualify as open - such as whether one should accept Alice's invitation to her party. With respect to them, it would be very difficult to argue that we do not have any resources to help us in reaching an intelligent, reasoned answer. Whatever the resources that we use to answer such mundane open questions are - and I shall say more on this presently - they are sufficient to provide a reasonable ground for deliberation and possible, reasonable disagreement. So the objection must mean something else, and this "else" is the divide to which I just pointed above: the objection must apply not to all open questions, declared unanswerable - for this would be factually mistaken-but only to those that we have defined as in principle open, ultimate questions, closed under further questioning - in short, to the philosophical ones in a more interesting sense of the qualification. This divide is very controversial, but suppose such a preparatory move, by the objection, is acceptable. The 
restriction in scope is not inconceivable, but it does underestimate two factors quite seriously, and hence very implausibly.

First, we saw in the previous section that questions do not occur in isolation. To put it in more Quinean terms, we always deal with a web of questions, posing or presupposing each other. In such a web or network, we saw that philosophical questions as ultimate, open questions, closed under questioning, do have a privileged role because of their influence, but they are not detached from other questions. This is important in terms of two kinds of constraint. Non-ultimate, open questions as well as empirical and logico-mathematical questions receive answers that constrain the space available for answering philosophical questions of an ultimate kind, the philosophical ones declared unanswerable by the objection. As in a Sudoku puzzle, once the easiest answers start piling up, constraints facilitate answering more difficult questions, and so forth. This is why we actually live our lives with our philosophical questions answered by default, perhaps only implicitly and uncritically, through our practices, choices, lifestyles, belief presuppositions, and so forth. We do not usually keep a stack of ultimate questions in a state of suspension. Living is living philosophically, no matter how badly. So much so that philosophy often begins by challenging our default answers.

Second, the way in which we go about answering mundane, simple, indeed even trivial, open questions points in the right direction when it comes to identifying what resources we can use to deal with ultimate, open questions. Empirical and logico-mathematical resources are likely to be necessary constraints, but they are insufficient. The kind of resource missing has many names in philosophy, and it is here that misunderstanding may occur quite easily. If I were to speak of myths, stories, or narratives, readers would justifiably raise their eyebrows, for this is too vague. In section 4, we saw that Uygur referred to "discourses embodying these concepts," and indeed, in modern terminology, one could speak of ideas and conceptions, judgments or considerations, but still be found wanting, for this is too restricted. Referring to thoughts, mental states, intuitions, common sense, language-games, semantic practices, or some post-Gettier doxastic vocabulary would mean being even more short-sighted. Cassirer's symbolic forms are perhaps too grandiose, as Weltanschauung and cultural milieu are. The suggestion by Dummett $(2010,10)$ that "the philosopher's only resource is the analysis of concepts we already possess" seems to approach the problem correctly (resource orientation) but fails to be sufficiently inclusive. Yet I hope that these examples start delineating a profile with which the reader is de facto well-acquainted.

The resources to which I am referring do include Alice's beliefs, what Bob read on the web, their cultural background, their language, religion, and art, their social practices, their memories of what was, and their expectations about what will be, their emotional intelligence, their past experiences, and so forth. It is the world of mental contents, conceptual 
frameworks, intellectual creations, intelligent insights, dialectical reasonings. I do not know a word that captures this resource very well. In other contexts, I have spoken about it in terms of semantic artefacts: the totality of the outcome of our creative semanticisation (giving meaning to and making sense of) and conceptual design of reality. Yet this will not do in this article, where we need an inclusive adjective, comparable to "empirical" and "logico-mathematical" in terms of scope and level of abstraction (more on the latter in the next section). So let me suggest we opt for noetic. ${ }^{10}$ It is because of the noetic nature of the resources required to answer philosophical problems that the latter have always tended to be seen more akin to logico-mathematical problems than to empirical ones. Let me quote Dummett one more time: "Philosophy shares with mathematics the peculiarity that it does not appeal to any new sources of [empirical (my addition)] information but relies solely upon reasoning on the basis of what we already know" $(2010,10)$. Dummett's "what we already know" is part of what I have called noetic resources. Philosophical questioning, as I wish to present it in this article, begins by acknowledging one irreducible fact: the permanent nature of informed, rational, and honest disagreement about significant questions, relevant to our lives. These are the questions that I have defined as open to reasonable disagreement, closed under questioning, and ultimate in terms of influence on other questions when it comes to answering them. We have just seen that they are the ones that may be constrained by empirical and logicomathematical resources but require noetic resources to be answered. Critics fail to grasp that philosophy is not in the business of discovering solutions but in that of designing them. We rely on semantic artefacts to formulate, discuss, and make sense of open questions, such as the ones Russell and Hawking list, and then to design and assess answers for them. And since the world is becoming more complicated not less, the philosophical space between the empirical and the logico-mathematical is growing, not shrinking.

In light of the third objection, we can refine even further the last version of our definition by saying that philosophical questions are in principle open, ultimate questions, closed under further questioning, possibly constrained by empirical and logico-mathematical resources, which require noetic resources to be answered. This is an improvement, but we have not yet completed our task. There is one last objection that needs to be taken seriously, because the analysis developed so far fails to provide any means

${ }^{10}$ As in the case of logico-mathematical information, the careful reader may wonder what kind of information is noetic information. I take it to satisfy the definition provided in Floridi 2011: well-formed, meaningful, and truthful data. Note that truthful, however, needs to be understood in the realist, constructionist, but "correctness" sense defended in Floridi 2010 and Floridi 2011, as any realist, representationalist, but correspondentist theory will probably not work. Moore seems to adopt a similar approach in his Principia, see now Moore 1993. 
to discriminate between good and bad philosophical questions. This is what we shall see in the next section.

\section{Fourth Objection: Open Questions Are Indiscriminate}

We saw that questions (and answers) never occur in a vacuum but are always embedded in a network of other questions (and answers). ${ }^{11}$ Likewise, they do not occur out of any context, without any purpose, or independently of any particular perspective, what I have called above a level of abstraction (LoA). So open questions may be "bad" questions when they are asked in the wrong context or for the wrong purpose. In both cases, philosophers tend to be social bores or gadflies, but such a faux pas has nothing to do yet with the answerable nature of open question. What does matter here is whether an open question, assuming it is a valid question, that is, properly formulated,${ }^{12}$ is asked at the right LoA. This difficulty requires a short diversion in order to introduce the very idea of a LoA. ${ }^{13}$

Imagine the following scenario. You ask a question about the price of an item, let's say a second-hand car, and you receive the following answer: 5,000 . The question concerned a variable, the price $x$ of the car in question, and you received an exact numerical value for $x$, yet something is missing. You still have no idea about the price because you do not know the type of the variable: is it British pounds, U.S. dollars, euros . . . ? Of course, the context usually helps. If you are in England and you are asking a car dealer, your question should be understood as concerning the price in British pounds, and so should the answer. This is trivial, you may think. Grice's conversational rules obviously apply. It is, and they do. But this is also a crucial assumption, easily forgotten. In November 1999, NASA lost the $\$ 125$ million Mars Climate Orbiter (MCO) because the Lockheed Martin engineering team used English (also known as Imperial) units of measurement, while NASA's team used the metric system for a key spacecraft operation. As a result, the MCO crashed into Mars. ${ }^{14}$ Assuming that contexts will always disambiguate the types of your variables paves the way to costly mistakes. So what has all this got to do with bad open questions? Quite a lot, as it turns out: bad open questions are absolute questions, that is, questions that are formulated with no regard for the

11 The erotetic implication, when answers are also included, covers the three cases analyzed in Wiśniewski 1994: the relation of implication of a question by a question and a set of declarative sentences, namely, answers or questions and answers; the relation of implication of a question by a question; and the relation of strong implication of a question by a question and a set of declarative sentences (ditto).

${ }^{12}$ Cohen 1929 provides an early analysis of invalid questions, such as "Who discovered America in 1491?"

13 The interested reader is referred to Floridi 2008 and Floridi 2011.

14 "Mars Climate Orbiter Mishap Investigation Board Phase I Report." NASA press release, ftp://ftp.hq.nasa.gov/pub/pao/reports/1999/MCO_report.pdf 
kind of LoA at which their possible answers become sensible. They are like questions asking for the absolute or "real" price of a car, impatient for any specification of any currency. The following two examples should help to clarify the mistake.

Consider Kant's classic discussion of the "antinomies of pure reason." As is well known, each of the four antinomies comprises a thesis and an antithesis, which are supposed to be both reasonable and irreconcilable. I list them here by slightly adapting their formulation from Kant's Critique of Pure Reason (Kant 1998):

1) Thesis: the world is finite; it has a beginning in time and is limited in space.

Antithesis: the world is infinite, it has no beginning in time and no limit in space (A 426-27/B 454-55).

2) Thesis: the world is discrete; everything in the world consists of elements that are ultimately simple and hence indivisible.

Antithesis: the world is continuous; nothing in the world is simple, but everything is composite and hence infinitely divisible (A 434-35/ B 462-63).

3) Thesis: there is freedom; to explain causal events in the world it is necessary to refer both to the laws of nature and to freedom.

Antithesis: there is no freedom; everything that happens in the world occurs only in accordance with natural causation (A 444 45/B 462-63).

4) Thesis: there is in the world an absolutely necessary Being.

Antithesis: there is nothing necessary in the world, but everything is contingent (A 452-53/B 480-81).

One may take each thesis and antithesis as an answer to the corresponding question. As Kant argues, the conflict is not between empirical experience and logical analysis. Rather, the four antinomies are generated by an unconstrained request (recall: we are treating philosophical questions as genuine requests for information) for unconditioned answers to fundamental problems concerning (1) time and space, (2) complexity/granularity, (3) causality and freedom, and (4) modality. And this is where Kant's transcendental method and the method of LoAs converge: the attempt to strive for something unconditioned is equivalent to the natural, yet profoundly mistaken, endeavour to analyse a system (reality in itself, for Kant, but it could also be a more limited domain) independently of any (specification of) the LoA at which the analysis is being conducted, the questions are being posed, and the answers are being offered, for a specified purpose. In other words, bad open questions are questions that try to avoid, or overstep, the limits set by any relevant LoA.

Second example. Closer to our time, Turing is probably the first to have introduced the method of abstraction in philosophy, at least in terms of 
influence (Floridi 2012a). He made clear, for the first time, how philosophical questions could be answered only by fixing the LoA at which it would then make sense to receive an answer. This is one of the greatest and lasting contributions of his famous test (Turing 1950), far more important than the incorrect predictions about when machines would pass it, or what consequences one should draw if they did pass it (Floridi, Taddeo, and Turilli 2009). It is sometimes forgotten that Turing refused even to try to provide an answer to the question "Can a machine think?" because he considered it a problem "too meaningless to deserve discussion" (Turing 1950, 442). Recall what Uygur said about the question "Is consciousness a mechanism or organism?" Using our simple example, in both cases it would be like asking the price of the second-hand car in absolute figures, insisting that no currency is used in order to express it. Nonsense. Likewise, Turing objected that the question involved vague concepts such as "machine" and "thinking." In other words, it was an open question that lacked a clear LoA. So Turing suggested replacing it with the imitation game, which is exactly more manageable and less demanding because it fixes a rule-based scenario easily implementable and controllable (Moor 2003). By so doing, he specified a LoA - the "currency" he chose for the game was human intelligence, but it could have been something else, from animal intelligence to human creativity, as many other versions of the Turing imitation game have shown - and asked a new open question, which may be summed up thus: "May one conclude that a machine is thinking, at the Level of Abstraction represented by the imitation game?" This is an open question well formulated.

After half a century, philosophy is still learning that absolute, open questions are bad philosophical questions not worth asking, as the following quotation from Quine indicates:

The very notion of an object at all, concrete or abstract, is a human contribution, a feature of our inherited apparatus for organizing the amorphous welter of neural input. ... Science ventures its tentative answers in man-made concepts, perforce, couched in man-made language, but we can ask no better. The very notion of object, or of one and many, is indeed as parochially human as the parts of speech; to ask what reality is really like, however, apart from human categories, is self- stultifying. It is like asking how long the Nile really is, apart from parochial matters of miles or meters. (Quine 1992, 6 and 9)

Too often, philosophical debates seem to be caused by a lack of, or misconception about, the right LoA at which the open questions should be addressed. Absolute (i.e., not properly LoA-constrained) questions generate absolute messes. Many pseudo-philosophical puzzles can be dismissed as mere muddles caused by a lack of LoA. This is not to say that the method of LoA represents a panacea. Disagreement is often genuine and not based on confusion, but chances of resolving or overcoming it, or 
at least of identifying a disagreement as irreducible, may be enhanced if one is first of all careful about specifying the LoA at which the open question is being formulated and therefore what answers it is sensible to expect in the first place. ${ }^{15}$

We are now ready for the final version of the definition: philosophical questions are in principle open, ultimate but not absolute questions, closed under further questioning, possibly constrained by empirical and logico-mathematical resources, which require noetic resources to be answered. All that remains to do now is to look at some of the consequences of this definition for our conception of philosophy.

\section{Conclusion: Philosophy as Conceptual Design}

The definition of philosophical questions at which we have arrived by adopting a resource-oriented approach has several advantages. I shall outline some of them here rather briefly. I suspect they may be more easily appreciated by doing some philosophy in such an informational way.

To begin with, approaching philosophical problems as open questions helps to explain the development of philosophy itself. Through time, philosophy outsources questions whose answers turn out to require not noetic but empirical or logico-mathematical resources. I am oversimplifying, of course, since usually many questions tend to require all three kinds of resources anyway, but I hope the point is sufficiently clear: there was a time when many questions we consider nowadays scientific, that is, closed, were taken to be philosophical, that is, open, from astronomy to medicine, from psychology to zoology. At the same time, philosophy insources new or renewed open questions, generated by the history of humankind, its development, discoveries, inventions, new semantic artefacts, new answers to empirical or logico-mathematical questions, and so forth. It is, in other words, a two-way trade between open and closed questions. The geographical discoveries and their cultural impact, the scientific revolution, the Enlightenment, new social, political, and economic conflicts, the debate on the foundations of mathematics and physics, the energy and environmental crises, and, as I have argued recently (Floridi 2011, Floridi forthcoming $a$ ), the information revolution are all significant examples of macroscopic sources of new open questions addressed by philosophy. Like a living heart, philosophy goes through a cycle of systole and diastole, contraction and dilation, outsourcing and insourcing of problems and solutions. Of course, looking at only half the cycle, like a sort of long and agonising contraction, leads people to declare such a heart dead or at best dying. The mistake should now be obvious. Because philosophy works in cycles and does not move in a straight line, it is preferable to see the history

15 The careful reader will have understood that this whole article is an attempt to set the right LoA at which to answer the question about the nature of philosophical questions. 
of philosophy as a matter of evolution of the semantic artefacts we develop to deal with open questions, rather than a matter of progress. In the long run, regardless of how many ups and downs, steps forward and steps back, revolutions and counter-revolutions, progress in science is measured in terms of the accumulation of answers to closed questions, answers that are no longer genuinely open to informed, rational, and honest disagreement: "[R]eal questions . . . can always be shown by proper analysis that they are capable of being solved by the methods of science, although we may not be able to apply these methods at present for merely technical reasons. We can at least say what would have to be done in order to answer the question even if we cannot actually do it with the means at our disposal. In other words: problems of this kind have no special 'philosophical' character, but are simply scientific questions. They are always answerable in principle, if not in practice, and the answer can be given only by scientific investigation" (Schlick 1932, 2:221). Still, in the long run, evolution in philosophy is measured in terms of accumulation of answers to open questions, answers that remain, by the very nature of the questions they address, open to reasonable disagreement. So those jesting that philosophy has never "solved" any problem but remains for ever stuck in endless debates, that there is no real progress in philosophy, clearly have no idea of what philosophy is about. They may as well complain that their favourite restaurant is constantly refining and expanding its menu.

The cyclical, progressive nature of philosophy leads to a further consideration. Because philosophy formulates new open questions and designs new answers, or revises old open questions and redesigns their answers, by being in a two-way interaction with its time, it is better to understand philosophy as a timely rather than a timeless study of open questions. ${ }^{16}$ This is not an invitation to follow intellectual fashions but a reminder that living philosophy needs to interact with open problems by being careful not to lose sight of their long-term relevance (context) and purposefulness (human interest). Anything else is historical curation: the preservation, maintenance, and study of the noetic assets accumulated by humanity to answer open questions. It is a vital task, given that arsonist vandalism seems a constant temptation, but it should not be confused with the actual production of such assets. Only the latter qualifies philosophy as the source of conceptual innovation. Of course, there remains one sense in which philosophy, understood as the study of open questions, is, at its best, everlasting. This is when philosophy is not disconnected from its time (timeless) but is so well connected (timely) to human interests as to withstand its own outdating. After all, philosophy as the study of open questions is eschatological by nature: we saw that the open questions that

16 "If by philosophia perennis we are to understand the permanence of questions of philosophy, then philosophy is the very reverse of perennis; it possesses no fixed framework because it is constantly renewed through fresh questions" (Uygur 1964, 64). 
matter most are the ultimate ones. So a classic in philosophy offers answers that retain their value long after they have been articulated, and can be repurposed in new contexts. Philosophia perennis means philosophy you can hack. ${ }^{17}$ We would not be reading the Republic, the Nicomachean Ethics, the Meditations, or the Critique of Pure Reason otherwise.

Once we realise that philosophical questions are those open to reasonable disagreement, it is a simple act of humble rationality to admit the possibility that other answers may be equally acceptable, sometimes preferable. This is not relativism, for it is perfectly feasible to assess the value of different answers and to deliberate on their respective merits. Recall the example of the restaurant above. It is rather a matter of tolerance. Yet such tolerance is not boundless. For we have seen that empirical and logico-mathematical resources as well as other answers in the networks of questions make philosophy, as the "science" of open questions, respectful of the empirically true, the mathematically proved, and the logically valid. It is a very bad philosophy indeed that disregards or even disparages some of the highest achievements of human intellect. Here, I fully subscribe to the conclusions reached by Mulligan, Simons, and Smith in "What's Wrong with Contemporary Philosophy?" Let me take the liberty to quote their splendid text extensively:

The honest pioneering spirit of the early and constructive phase of AP [analytic philosophy] had its close parallels also in the early phenomenologists, so much so that a century ago there existed no gulf between them. And it is precisely this spirit that must be rekindled. Philosophers should learn and practice their analytical skills. They should prize the theoretical virtues of consistency, analytic clarity, explanatory adequacy, and constrained simplicity, be aware of the historical depth and pitfalls of the ideas they are manipulating, and be wary of the assumption that everything new is better. They should trust to common sense, avoid bullshit, and beware celebrity. But above all they should lift their heads above philosophy: study and respect good science and good practice, and try to understand their implications. Like scientists, they should cooperate with one another and with other disciplines, and seek funding for cooperative research, aiming at theoretical comprehensiveness, using topic-neutral skills and knowledge to bridge compartments in knowledge. They should learn how to present ideas clearly to all kinds of audiences, and not just to fellow aficionados of the fake barn. Above all, philosophers should be humble, in the face of the manifest complexity of the world, the acumen of their philosophical predecessors and non-philosophical contemporaries, and their own fallibility. But with this humility they should be unwaveringly resolved to discover, however complex, frustrating and unlovely it may be, the truth. (Mulligan, Simons, and Smith 2006, 67)

"They should be unwaveringly resolved to discover . . the truth," that is, to give answers to the open questions we find so pressing. The overall

17 On semantic repurposing see Floridi forthcoming $b$. 
picture of philosophy that emerges from the previous pages is one of a constructive enterprise in which the analysis of open questions is not the whole task but the preparatory stage for the design (not invention, not discovery) of satisfactory answers. In the past, philosophers had to take care of the whole chain of knowledge production, from raw data to scientific theories, as it were. Throughout its history, philosophy has progressively identified classes of empirical and logico-mathematical problems and closed questions, and has outsourced their investigations to new disciplines. It has then returned to these disciplines and their findings for controls, clarifications, constraints, methods, tools, and insights but, pace Carnap (1935; see especially the chapter entitled "The Rejection of Metaphysics") and Reichenbach (1951), philosophy itself consists of conceptual investigations whose essential nature is neither empirical nor logicomathematical. In philosophy, one neither tests nor calculates. Philosophy "does not make any observations or conduct any experiments of its own" (Dummett 2010, 7). So philosophy is not a conceptual aspirin, a superscience, or the manicure of language. Its method is conceptual design, that is, the art of identifying and clarifying open questions and of designing, proposing, and evaluating explanatory answers. It is in this (scholarly incorrect but more interesting $)^{18}$ sense that I like to interpret Schlick's distinction between science as the pursuit of truth and philosophy as the pursuit of meaning. Philosophy is, after all, the last stage of reflection, where the semanticisation of Being is pursued and kept open (Russell 1912, chap. 15). Its critical and creative investigations identify, formulate, evaluate, clarify, interpret, explain but above all answer questions that are intrinsically capable of different and possibly irreconcilable treatments, questions that are genuinely open to informed, rational, and honest disagreement, even in principle. It is a constructive enterprise, whose investigations are often entwined with empirical and logico-mathematical issues, and so scientifically constrained, but, in themselves, they are neither. They constitute a space of inquiry broadly definable as normative. It is an open space: anyone can step into it, no matter what the starting point is, and disagreement is always possible. It is also a dynamic space, for when its cultural environment changes, philosophy follows suit and evolves.

It matters enormously whether a culture, a civilization, or a society is friendly towards philosophy as "the attempt to answer such ultimate questions," that is, as the study of open questions, which designs conceptual artefacts to answer them. One way of understanding the incipit of Aristotle's Metaphysics, that "All men by nature desire to know," is to realise that we all wish to have our open questions answered. Humanity cannot bear such a semantic vacuum. So the serious risk is that, if philosophy does not address such open questions, someone else will. Those

${ }^{18}$ Schlick 1932, 2:222. Of course Schlick ends up interpreting philosophy as a semantic activity, a conclusion I tried to show to be evitable. 
who oppose philosophy are consigning to a bad philosophical treatment all the ultimate, open questions whose answers guide most of our lives. They should realise that dubious gurus, religious fundamentalists, impostors, and charlatans of all kinds will step in. The fight against philosophy is a fight for obscurantism. ${ }^{19}$ If you play with Hume's fire, you will get burned.

\author{
School of Humanities \\ University of Hertfordshire \\ de Havilland Campus \\ Hatfield, Herts AL10 9AB \\ United Kingdom \\ l.floridi@herts.ac.uk
}

\title{
Acknowledgments
}

I discussed previous versions of this article as a speaker at the meeting "The Editor's Cut: A View of Philosophical Research from Journal Editors," organised by the Institute of Philosophy, School of Advanced Study, University of London (London, 13 January 2012); at the Philosophy Lecture Series, organised by the Department of Philosophy at St Mary's University College, University of London, and the Royal Institute of Philosophy (London, 1 February 2012); and at the Cumberland Lodge meeting, organised by the Philosophy Society, University of Hertfordshire (Cumberland Lodge, 17 February 2012). I am indebted to Barry C. Smith, Yasemin J. Erden, and Brendan Larvor, respectively, for their kind invitations, and to the participants in these meetings for the fruitful opportunity to discuss my ideas and to receive much helpful feedback.

\section{References}

Belnap, N. D., and T. B. Steel. 1976. The Logic of Questions and Answers. New Haven: Yale University Press.

Carnap, R. 1935. Philosophy and Logical Syntax. London: Kegan Paul, Trench, Trubner.

Cohen, F. S. 1929. "What Is a Question?" Monist 39, no. 3: 350-64.

D'Agostino, M., and L. Floridi. 2009. "The Enduring Scandal of Deduction: Is Propositional Logic Really Uninformative?" Synthese 167, no. 2: 271-315.

19 This is lucidly argued in Wood 2006. I agree with Wood that philosophy should closely collaborate with science, society, and its own history in its fight against the dark forces of stupidity. 
Dennett, D. C. 2006. "Higher-Order Truths About Chmess." Topoi 25, nos. 1-2: 39-41.

Dewey, R. E. 1956. “The Future of Philosophy.” Journal of Philosophy 53, no. 5: 187-96.

Dummett, M. 2010. The Nature and Future of Philosophy. New York: Columbia University Press.

Floridi, L. 1996. Scepticism and the Foundation of Epistemology: A Study in the Metalogical Fallacies. Leiden: Brill.

. 1999. Philosophy and Computing: An Introduction. London: Routledge.

_. 2008. "The Method of Levels of Abstraction." Minds and Machines 18, no. 3: 303-29.

- 2010. "Semantic Information and the Correctness Theory of Truth." Erkenntnis 74, no. 2: 147-75.

. 2011. The Philosophy of Information. Oxford: Oxford University Press.

—. 2012a. "Turing's Three Philosophical Lessons and the Philosophy of Information." Philosophical Transactions A 370:353642.

—. 2012b. "Degenerate Epistemology." Philosophy \& Technology 25, no. 1: 1-3.

Forthcoming $a$. The Ethics of Information. Oxford: Oxford University Press.

- Forthcoming $b$. "Perception and Testimony as Data Providers." Logique et Analyse.

Floridi, L., M. Taddeo, and M. Turilli. 2009. "Turing's Imitation Game: Still a Challenge for Any Machine and Some Judges." Minds and Machines 19, no. 1: 145-50.

Fortnow, L., and S. Homer. 2003. "A Short History of Computational Complexity." Bulletin of the EATCS 80:95-133.

Glaeser, F. 1969. "The Future of Philosophy." Philosophy and History 2, no. 2: 166-69.

Hawking, S. W., and L. Mlodinow. 2010. The Grand Design. London: Bantam Press.

Hintikka, J. 1973. Logic, Language-Games and Information: Kantian Themes in the Philosophy of Logic. Oxford: Clarendon Press.

Hume, D. 2000. An Enquiry Concerning Human Understanding: A Critical Edition. Edited by Tom L. Beauchamp. In The Clarendon Edition of the Works of David Hume. Oxford: Clarendon Press. (Includes bibliographical references [pp. 281-306] and indexes.)

Kant, I. 1998. Critique of Pure Reason. Translated and edited by Paul Guyer and Allen Wood. In The Cambridge Edition of the Works of Immanuel Kant. Cambridge: Cambridge University Press.

Llewelyn, J. E. 1964. "What Is a Question?" Australasian Journal of Philosophy 42, no. 1: 69-85. 
Moor, J. 2003. The Turing Test: The Elusive Standard of Artificial Intelligence. Dordrecht: Kluwer Academic.

Moore, G. E. 1993. Principia Ethica. Revised edition with "Preface to the Second Edition" and Other Papers. Edited by T. Baldwin. Cambridge: Cambridge University Press. (First edition published in 1903.)

Mulligan, K., P. Simons, and B. Smith. 2006. "What's Wrong with Contemporary Philosophy?" Topoi 25, nos. 1-2: 63-67.

Norris, C. 2011. "Hawking Contra Philosophy." Philosophy Now 82:2124.

Pearl, J. 1984. Heuristics: Intelligent Search Strategies for Computer Problem Solving. Reading, Mass.: Addison-Wesley.

Quine, W. V. 1992. "Structure and Nature." Journal of Philosophy 89, no. 1: 5-9.

Reichenbach, H. 1951. The Rise of Scientific Philosophy. Berkeley: University of California Press.

Russell, B. 1912. The Problems of Philosophy. Oxford University Press: London.

Schlette, H. R., ed. 1968. Die Zukunft der Philosophie. Freiburg i. Br.: Olten.

Schlick, M. 1932. "The Future of Philosophy." College of the Pacific Publications in Philosophy 1:45-62. In Schlick 1979, 2:210-23. 1979. Philosophical Papers. 2 vols. Dordrecht: Reidel.

Sipser, M. 2012. Introduction to the Theory of Computation. 3rd ed. Boston: Cengage Learning.

Sorensen, R. A. 1993. Pseudo-Problems: How Analytic Philosophy Gets Done. London: Routledge.

Strandberg, C. 2004. "In Defence of the Open Question Argument." Journal of Ethics 8, no. 2: 179-96.

Turing, A. M. 1950. "Computing Machinery and Intelligence." Mind 59, no. 236: 433-60.

Uygur, N. 1964. "What Is a Philosophical Question?" Mind 73, no. 289: 64-83.

Whitehead, A. N. 1978. Process and Reality: An Essay in Cosmology. Corrected edition. New York: Free Press.

Wiśniewski, A. 1994. "Erotetic Implications." Journal of Philosophical Logic 23, no. 2: 173-95.

Wood, A. 2006. "Philosophy, What Is to Be Done?" Topoi 25, nos. 1-2: 133-36. 